\title{
Study on Parameters of Consumer Preferences for Alternative Wheat Products (Gluten-Free Foods) in USA and India
}

\section{Jolly Masih}

State Trainer (Free-Lance) at UNICEF Project MAA (Mother's Absolute Affection), Jalandhar (Punjab), India

Email: jolly.iabm@gmail.com

How to cite this paper: Masih, J. (2018) Study on Parameters of Consumer Preferences for Alternative Wheat Products (Gluten-Free Foods) in USA and India. Agricultural Sciences, 9, 385-396. https://doi.org/10.4236/as.2018.94027

Received: January 26, 2018

Accepted: March 25, 2018

Published: March 28, 2018

Copyright $\odot 2018$ by author and Scientific Research Publishing Inc. This work is licensed under the Creative Commons Attribution International License (CC BY 4.0).

http://creativecommons.org/licenses/by/4.0/

\begin{abstract}
Celiac Disease (CD) is an inherited, autoimmune disorder in which proteins from the grains wheat, rye and barley (collectively called gluten) damage the small intestine. The only treatment for $\mathrm{CD}$ is a strict, lifelong gluten-free diet. With a prevalence rate of about one in $100-133$ people worldwide. Celiac disease is wide-spread across the globe. Unlike traditional allergies, which cause immediate reactions, gluten sensitivity is harder to pin down since it manifests gradually and in various forms like headaches, stomach cramps, bloating, anxiety, and depression. Due to complicated diagnosis procedure and lack of awareness, many cases are either misdiagnosed or not at all diagnosed in India and USA. In spite of high growth, gluten-free foods are facing problems to grain ground in Asian market, due to high price, lack of awareness about the products, large number of un-diagnosed cases and inefficient value chain for gluten-free products. One of the major issues in India and USA is very high prices of gluten-free foods as compared to regular food products. Globally, the market potential of gluten free products is estimated to be USD 4639.13 Million and USD 7594.43 Million in 2015 and 2020 respectively. The global gluten free food market is projected to grow with a CAGR between 9 percent and 10.2 percent during 2016-2022. The study on consumer preference of gluten-free foods would enable manufacturers of gluten-free foods to understand the current and evolving expectations of consumers and to design the products according. Study of two countries i.e., India and USA would enable manufacturers to understand the difference in choices and preferences related to gluten-free foods for both the nations. This study would help manufacturers of alternative wheat product to form the concrete marketing and product development strategy based on recent consumer behavior trends.
\end{abstract}




\section{Keywords}

Wheat, Gluten-Free, Alternative Wheat Products, Celiac Disease, Gluten Intolerance, Marketing, Gluten-Free Food

\section{Introduction}

Celiac Disease (CD) is an inherited, autoimmune disorder in which proteins from the grains wheat, rye and barley (collectively called gluten) damage the small intestine. The only treatment for $\mathrm{CD}$ is a strict, lifelong gluten-free diet. With a prevalence rate of about one in $100-133$ people worldwide [1]. Celiac disease is wide-spread across the globe. Research by Dr. Schar Institute, a leading company for gluten-free foods, has found celiac disease as an epidemic which is spreading in all the wheat consuming areas of the world. The estimated population prevalence of diagnosed celiac disease in many countries is nearly 1 percent and in many countries it has even reached $2-5$ percent [2]. Health authorities in the Western world and in developing countries must pay serious attention to this situation. Unlike traditional allergies, which cause immediate reactions, gluten sensitivity is harder to pin down since it manifests gradually and in various forms like headaches, stomach cramps, bloating, anxiety, and depression. Due to complicated diagnosis procedure and lack of awareness, many cases are either misdiagnosed or not at all diagnosed in India and USA. In spite of high growth, gluten-free foods are facing problems to grain ground in Asian market, due to high price, lack of awareness about the products, large number of un-diagnosed cases and inefficient value chain for gluten-free products. One of the major issues in India and USA is very high prices of gluten-free foods as compared to regular food products. Gluten-free foods are 242 - 500 percent more expensive than comparable, regular products, but now the difference has shrunk in few countries like USA due to improved availability of gluten-free foods. Gluten-free flours, baked goods and prepared foods are now 162 percent more costly than regular products [3]. Study by Canadian Celiac Association tells that some celiac patients resist gluten-free foods due to perceived low nutritive value as compared to gluten containing foods [4]. Makharia found that currently available gluten-free food in India have low nutritional level as they are being locally prepared and provides an opportunity for global brands to enter in this markets due to increased number of celiac patients, awareness about availability of international brands and improved incomes. America has wide range of products available from low nutritive to high nutritive value, but mostly people prefer cheap gluten-free products with low nutritive value [5].

Globally, the market potential of gluten free products is estimated to be USD 4639.13 Million and USD 7594.43 Million in 2015 and 2020 respectively. The global gluten free food market is projected to grow with a CAGR between 9 percent and 10.2 percent during 2016-2022. The North American region accounted 
for the largest share of the gluten-free products market worth USD 1985.72 million in 2014. A study was conducted to understand the buying behaviour of users of gluten-free food. It was found that 73 percent of consumers have not been diagnosed with Celiac Disease but they still consume gluten-free foods for health benefits like weight reduction, control over diabetes and high blood pressure. Approximately 27 percent used to consume gluten-free foods as they were gluten intolerant or sensitive [6].

The study on consumer preference of gluten-free foods would enable manufacturers of gluten-free foods to understand the current and evolving expectations of consumers and to design the products according. Study of two countries i.e., India and USA would enable manufacturers to understand the difference in choices and preferences related to gluten-free foods for both the nations. This study would help manufacturers of alternative wheat product to form the concrete marketing and product development strategy based on recent consumer behavior trends.

\section{Methodology}

Nature of research: Since the study aimed to explore the consumer preferences related to gluten-free foods, it was exploratory in nature.

\section{Sources of data:}

Primary source: Total number of consumers surveyed in the research were 550 (400 from India + 150 from USA).

Selection of customers: Population of USA is 320.09 million and population of India is 1.18 billion which is nearly thrice the population of USA (Wikipedia, 2015). Thus making a ratio of 1:3. Judgmental sampling and snowball sampling was used to reach potential customers of gluten-free foods. Minimum sample size calculation procedure was conducted based on population of both the countries. Customers who use gluten-free foods including celiac patients, patients of allergies like wheat allergy, lactose intolerance, patients of autism, depression and other health conscious people consuming gluten-free foods for health benefits were taken for study. As complete information was not available in the form of registered number of patients or customers. So with the help of reference potential customers were considered for study. In India, 100 customers were covered from each city making a total of 400 customers. In USA, 50 customers were covered from each city making a total of 150 customers. Thus meeting the ratio of nearly 1:3 as per the ratio of the population. Total number of consumers surveyed in the research was 550 (400 from India +150 from USA).

Secondary source: Data from websites of Celiac Society of India, Celiac Society of America, National Celiac Society of USA, Markets and Markets report, Mintel and Nielsen database. Data was taken from January 2013 to December 2017.

Research tools: Pre-scheduled questionnaire and in-depth interviews of con- 
sumers of gluten-free foods. Variables studied in the questionnaire and interview were: taste, smell, appearance, variants, nutrients, quality, price, availability, promotion, social status, doctor's recommendation, retailers recommendation, knowledge, brand image, food safety certification, associated claims along with gluten-free food, packaging, labelling information and influence of other users.

Research technique: Factor analysis was done for consumers' responses, using principal component extraction method with Varimax rotation, to explain the variance. Using the factor loadings, the statements were grouped into respective factors and were renamed according to their collective representation. If the variables are standardized, the factor analysis model may be represented as:

$$
X i=A i 1 F 1+A i 2 F 2+A i 3 F 3+\cdots+A i m F m+V i U i
$$

where, $X i=i$ th standardized variable

$A i j=$ standardized multiple regression coefficient of

Variable $i$ on common factor $j$

$F=$ common factor

$V i=$ standardized regression coefficient of variable $i$ on unique factor $i$

$U i=$ the unique factor for variable $i$

$m=$ number of common factors

Following factors were considered to understand purchase decision of gluten-free (GF) products according to Mintel Data (2014): taste, smell, appearance, variants, nutrients, quality, price, availability, promotion, social status, doctor's recommendation, retailers recommendation, knowledge, brand image, food safety certification, associated claims along with gf, packaging, labeling information and influence of other users.

\section{Results \& Discussion}

\subsection{Factor Analysis Model to Study Consumer's Attitude towards Gluten-Free Foods in India}

Table 1 shows KMO and Bartlett's Test to study consumer's attitude towards gluten-free foods in India. India Bartlett's Test of Sphericity was 0.000 ( $\mathrm{p}<$ 0.001) thus variables has pattern of relationship. Kaiser-MeyerOlkin Measure (KMO) of Sampling Adequacy should be greater than 0.50 because if KMO value was less than 0.5 than distinct and reliable factors could not be produced. KMO more than 0.5 indicated that model has produced reliable factor. In this case $\mathrm{KMO}$ is $\mathbf{0 . 7 8 5}$, thus our model has produced distinct and reliable factors. In correlation matrix for India, correlations that were above $r=+/-0.90$ indicated multicollinearity. Determinant score above 0.00001 indicated an absence of multicollinearity. In case of India the determinant value was $7.31 \mathrm{E}-005$, which means 0.0000731 , thus the sample did not have multicollinearity.

Table 2 represents total variance explained by variables for consumer's attitude towards gluten-free foods in India. The eigen values associated with each factor represented the variance explained by that particular linear component. 
Table 1. KMO and Bartlett's Test to study consumer's attitude towards gluten-free foods in India.

\begin{tabular}{lcc}
\hline Kaiser-Meyer-Olkin Measure of Sampling Adequacy. & 0.785 & 3738.158 \\
& ApproZ. Chi-Square & 136 \\
Bartlett's Test of Sphericity & Df & Sig. \\
& & 0.000 \\
\hline
\end{tabular}

Source: Researcher's own compiled primary data.

Table 2. Total variance explained by variables for consumer's attitude towards gluten-free foods in India.

\begin{tabular}{|c|c|c|c|c|c|c|c|c|c|}
\hline \multirow[b]{3}{*}{ Component } & \multicolumn{8}{|c|}{ Total Variance Explained } & \\
\hline & \multicolumn{3}{|c|}{ Initial Eigenvalues } & \multicolumn{3}{|c|}{ Extraction Sums of Squared Loadings } & \multicolumn{3}{|c|}{ Rotation Sums of Squared Loadings } \\
\hline & Total & $\begin{array}{l}\text { Percent of } \\
\text { Variance }\end{array}$ & $\begin{array}{c}\text { Cumulative } \\
\text { percent }\end{array}$ & Total & $\begin{array}{l}\text { Percent of } \\
\text { Variance }\end{array}$ & $\begin{array}{c}\text { Cumulative } \\
\text { percent }\end{array}$ & Total & $\begin{array}{l}\text { Percent of } \\
\text { Variance }\end{array}$ & $\begin{array}{c}\text { Cumulative } \\
\text { percent }\end{array}$ \\
\hline 1 & 4.599 & 27.050 & 27.050 & 4.599 & 27.050 & 27.050 & 3.326 & 19.566 & 19.566 \\
\hline 2 & 3.103 & 18.253 & 45.303 & 3.103 & 18.253 & 45.303 & 3.027 & 17.803 & 37.370 \\
\hline 3 & 2.408 & 14.164 & 59.467 & 2.408 & 14.164 & 59.467 & 2.597 & 15.278 & 52.648 \\
\hline 4 & 1.022 & 6.014 & 65.481 & 1.022 & 6.014 & 65.481 & 2.182 & 12.833 & 65.481 \\
\hline
\end{tabular}

Extraction Method: Principal Component Analysis. Source: Researcher's own compiled primary data.

Eigen values displayed in terms of percentage of variance explained. The first factor explained relatively large amount of variance than other factors.

Rotation helped in optimizing the factor structure, Rotated Sums of Squared Loadings were considered. In case of India, total 4 factors were extracted based to consumer behaviour attributes. Gluten-free foods were mostly prevalent in Northern India and in some parts of Southern India.

In variance matrix, in Rotated Sums of Squared Loadings column, it was visible that factor 1 contributed to 19.56 percent of variance, followed by factor 2 (17.80 percent variance), factor 3 (15.27 percent variance) and factor 4 (12.83 percent variance).

Figure 1 shows scree plot for factors extracted after rotation of variables for consumer's attitude towards gluten-free foods in India. The scree plot is shown with an arrow indicating point of inflexion on curve. Graph clearly showed that there are four factors before a stable plateau is reached.

Table 3 shows component matrix for extracted factors after rotation of variables for consumer's attitude towards gluten-free foods in India. Rotated component matrix has same information as the component matrix except that it is calculated after rotation. Before rotation, most variables were loaded highly onto first factor and remaining factors did not get much weightage. However after rotation the factor scores were re-distributed and improved. All factor got weightage according to variable being loaded on them.

Awareness, brand image, food safety certification, packaging options and other users in vicinity variables loaded on factor 1 . Thus factor 1 could be named as 


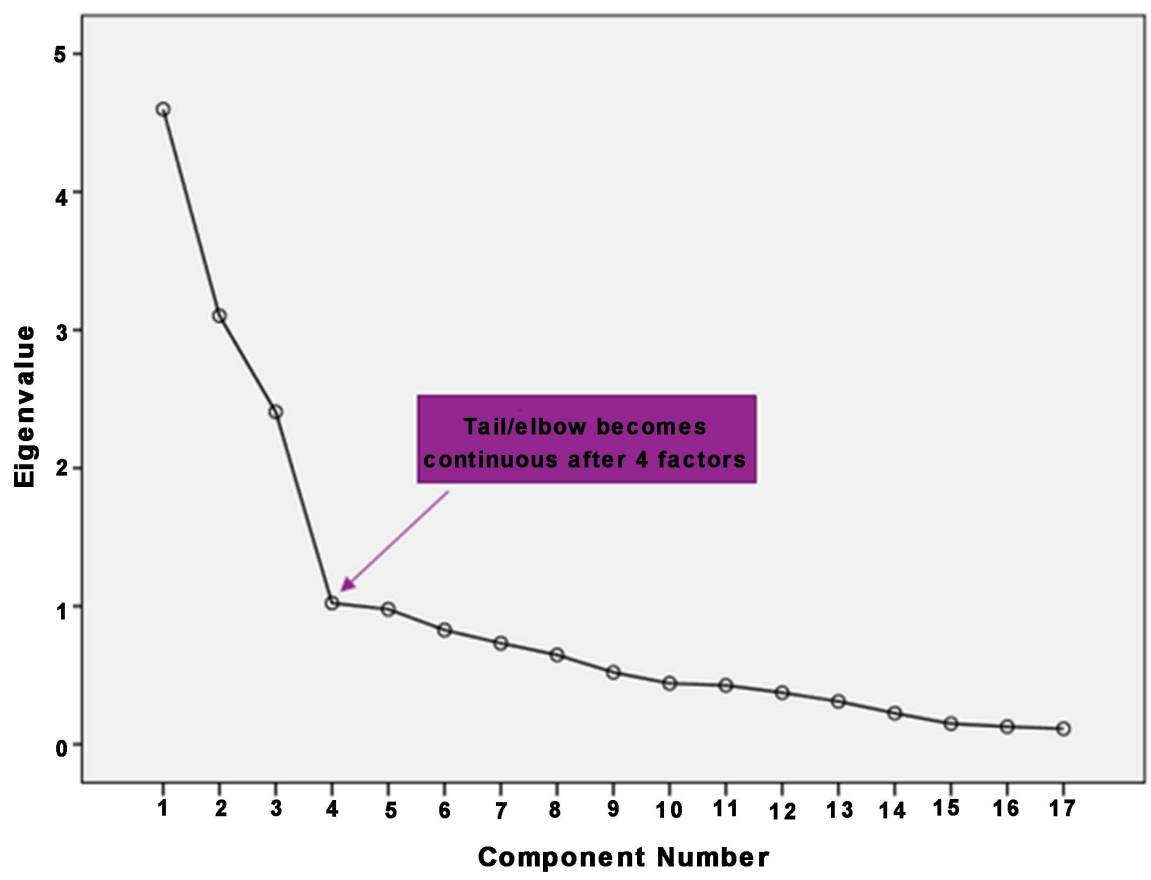

Figure 1. Scree Plot for factors extracted after rotation of variables for consumer's attitude towards gluten-free foods in India. Source: Researcher's own compiled primary data.

brand packaging. Factor 1 had maximum variance of 19.56 percent. Brand packaging was most important factor in India. Consumers were often driven towards attractive packaging with all information labelled. All successful national and international brands like Dr. Schar, Beewell, Wheafree had focus on multiple packaging options, creating good brand image and labelling food safety certifications to win the trust of consumers. Small packaging for snacks, bakery products and chocolates were highly demanded in small towns and rural areas since they were affordable.

Taste, smell, product appearance and quality loaded on factor 2 . Thus factor 2 could be named as Product Features. Factor 2 had variance of 17.80 percent. Consumers often made complaint about the lack of moisture, softness and taste in gluten-free foods. Thus there was acute need to develop gluten-free foods which were tasty, had good flavour and texture.

Availability, promotion, social status and doctor recommendation loaded on factor 3. Thus factor 3 could be named as Place \& Promotion. Factor 3 had variance of 15.27 percent. Many health conscious people look for gluten-free products in nearby store, thus brands like Wheafree which had wider distribution coverage captured more market. Gluten-free foods which were popular or were being recommended by doctor and celiac support groups were sold more. Consuming gluten-free foods or sugar-free foods was considered healthy and symbol of high status, which further increased their demand. Thus companies should focus to increase their distribution network and should come up with innovative promotion strategies. 
Table 3. Component matrix for extracted factors after rotation of variables for consumer's attitude towards gluten-free foods in India.

\begin{tabular}{|c|c|c|c|c|}
\hline \multicolumn{5}{|c|}{ Rotated Component Matrix } \\
\hline & \multicolumn{4}{|c|}{ Component } \\
\hline & 1 & 2 & 3 & 4 \\
\hline Taste & & 0.859 & & \\
\hline Smell & & -0.766 & & \\
\hline Product_appearance & . & 0.903 & & \\
\hline Quality & & 0.879 & & \\
\hline Price & & & & -0.430 \\
\hline Availability & & & 0.900 & \\
\hline Promotion & & & 0.922 & \\
\hline Social_status & & & 0.788 & \\
\hline Doctor_recommendation & & & 0.405 & \\
\hline Knowledge & & & & 0.575 \\
\hline Awareness & 0.791 & & & \\
\hline Brand_image & 0.838 & & & \\
\hline Food_safety_certification & 0.821 & & & \\
\hline Claims & & & & 0.747 \\
\hline Packaging_options & 0.695 & & & \\
\hline Labelling_information & & & & 0.774 \\
\hline Other_users_in_vicinity & 0.597 & & & \\
\hline
\end{tabular}

Extraction method: Principal component analysis. Rotation method: Varimax with kaiser normalization. a. Rotation converged in 5 iterations. Source: Researcher's own compiled primary data.

Price, knowledge, claims and labelling information recommendation loaded on factor 4 . Thus factor 4 could be named as pricing and labelling. Factor 4 had variance of 12.83 percent. High prices of gluten-free products were point of concern for many consumers. Celiac disease was found mostly in rural India where people were unable to afford costly gluten-free products, thus they started to look for cheaper options. In cities people looked for health benefits on packaging labels like weight management, low sugar, less cholesterol and high fiber. Thus, affordable gluten-free foods should be prepared to increase the consumer base. Detailed labelling and authentic claims might help in winning the faith of consumers.

\subsection{Factor Analysis Model to Study Consumer's Attitude towards Gluten-Free Foods in USA}

Table 4 shows KMO and Bartlett's Test to study consumer's attitude towards gluten-free foods in USA. Bartlett's Test of Sphericity (significant level of $\mathrm{p}<$ 0.05 ) is used to confirm that sample had pattern of relationships. In USA 
Table 4. KMO and Bartlett's Test to study consumer's attitude towards gluten-free foods in USA.

\begin{tabular}{lcc}
\hline \multicolumn{2}{c}{ Kaiser-Meyer-Olkin Measure of Sampling Adequacy. } & 0.639 \\
\hline \multirow{3}{*}{ Bartlett's Test of Sphericity } & ApproZ. Chi-Square & 781.907 \\
& Df & 136 \\
& Sig. & 0.000 \\
\hline
\end{tabular}

Source: Researcher's own compiled primary data.

Bartlett's Test of Sphericity was $0.000(\mathrm{p}<0.001)$ thus variables have pattern of relationship. Kaiser-Meyer-Olkin Measure (KMO) more than 0.5 indicate that model had produced reliable factor. In this case KMO was 0.639 , thus our model had produced distinct and reliable factors. In correlation matrix for USA, correlations that are above $r=+/-0.90$ indicate that data might have a problem of multicollinearity. Determinant score above 0.00001 indicated an absence of multicollinearity. In case of USA, the determinant value was 0.004 , thus the sample did not have multicollinearity.

Table 5 shows total variance explained by variables for consumer's attitude towards gluten-free foods in USA. The eigen values associated with each factor represent the variance explained by that particular linear component. In variance matrix, in Rotated Sums of Squared Loadings column, it was visible that factor one contributed to 16.87 percent of variance, followed by factor 2 (14.84 percent variance), factor 3 (11.58 percent variance), factor 4 (8.94 percent variance), factor 5 (7.05 percent variance) and factor 6 (6.36 percent variance). Overall 6 factors contributed to 65.60 percent variance).

Figure 2 shows scree plot for factors extracted after rotation of variables for consumer's attitude towards gluten-free foods in USA. The scree plot is shown with an arrow indicating point of inflexion on curve. Graph clearly showed that there were six factors before a stable plateau was reached.

Table 6 shows component matrix for extracted factors after rotation of variables for consumer's attitude towards gluten-free foods in USA. After rotation the factor scores were re-distributed and improved and all factor got weightage according to variable being loaded on them.

Food safety certification, claims, packaging options, labelling information and other users in vicinity variables loaded on factor 1 . Thus factor 1 could be named as Safe food attributes. Factor 1 had maximum variance of 16.73 percent. In USA number of consumers who suffered from some kind of allergies had increase many folds in past 5 years due to life style changes, weak metabolism, autoimmune disorders, high rate of medical diagnosis and increased awareness. These consumers along with other health conscious people looked for foods which were very well labelled about the ingredients they contain, claims like organic, Non-GMO etc. and were available in packaging according to their need. Thus safe food attributes was the most important factor in gluten-free foods market of USA. 
Table 5. Total variance explained by variables for consumer's attitude towards gluten-free foods in USA.

\begin{tabular}{|c|c|c|c|c|c|c|c|c|c|}
\hline \multicolumn{10}{|c|}{ Total Variance Explained } \\
\hline \multirow[b]{2}{*}{ Component } & \multicolumn{3}{|c|}{ Initial Eigenvalues } & \multicolumn{3}{|c|}{ Extraction Sums of Squared Loadings } & \multicolumn{3}{|c|}{ Rotation Sums of Squared Loadings } \\
\hline & Total & $\begin{array}{l}\text { Percent of } \\
\text { Variance }\end{array}$ & $\begin{array}{c}\text { Cumulative } \\
\text { percent }\end{array}$ & Total & $\begin{array}{l}\text { Percent of } \\
\text { Variance }\end{array}$ & $\begin{array}{c}\text { Cumulative } \\
\text { percent }\end{array}$ & Total & $\begin{array}{l}\text { Percent of } \\
\text { Variance }\end{array}$ & $\begin{array}{c}\text { Cumulative } \\
\text { percent }\end{array}$ \\
\hline 1 & 3.154 & 18.552 & 18.552 & 3.154 & 18.552 & 18.552 & 2.868 & 16.873 & 16.873 \\
\hline 2 & 2.596 & 15.270 & 33.821 & 2.596 & 15.270 & 33.821 & 2.525 & 14.854 & 31.727 \\
\hline 3 & 1.831 & 10.772 & 44.593 & 1.831 & 10.772 & 44.593 & 1.969 & 11.584 & 43.310 \\
\hline 4 & 1.464 & 8.611 & 53.204 & 1.464 & 8.611 & 53.204 & 1.521 & 8.949 & 52.259 \\
\hline 5 & 1.113 & 6.547 & 59.751 & 1.113 & 6.547 & 59.751 & 1.199 & 7.053 & 59.312 \\
\hline 6 & 1.008 & 5.929 & 65.680 & 1.008 & 5.929 & 65.680 & 1.083 & 6.368 & 65.680 \\
\hline
\end{tabular}

Extraction method: principal component analysis. Source: Researcher's own compiled primary data.

Table 6. Component matrix for extracted factors after rotation of variables for consumer's attitude towards gluten-free foods in USA.

\begin{tabular}{|c|c|c|c|c|c|c|}
\hline & \multicolumn{6}{|c|}{ Rotated Component Matrix } \\
\hline & \multicolumn{6}{|c|}{ Component } \\
\hline & 1 & 2 & 3 & 4 & 5 & 6 \\
\hline Taste & & 0.857 & & & & \\
\hline Smell & & -0.770 & & & & \\
\hline Product_appearance & & 0.784 & & & & \\
\hline Quality & & 0.618 & & & & \\
\hline Price & & & & & 0.821 & \\
\hline Availability & & & 0.891 & & & \\
\hline Promotion & & & 0.897 & & & \\
\hline Social_status & & & & 0.595 & & \\
\hline Doctor_recommendation & & & & & 0.609 & \\
\hline Knowledge & & & & & & 0.743 \\
\hline Awareness & & & & 0.805 & & \\
\hline Brand_image & & & & & & 0.510 \\
\hline Food_safety_certification & -0.853 & & & & & \\
\hline Claims & 0.894 & & & & & \\
\hline Packaging_options & -0.624 & & & & & \\
\hline Labelling_information & 0.732 & & & & & \\
\hline Other_users_in_vicinity & 0.436 & & & & & \\
\hline
\end{tabular}

Extraction method: Principal component analysis. Rotation method: Varimax with kaiser normalization. a. Rotation converged in 7 iterations. Source: Researcher's own compiled primary data. 


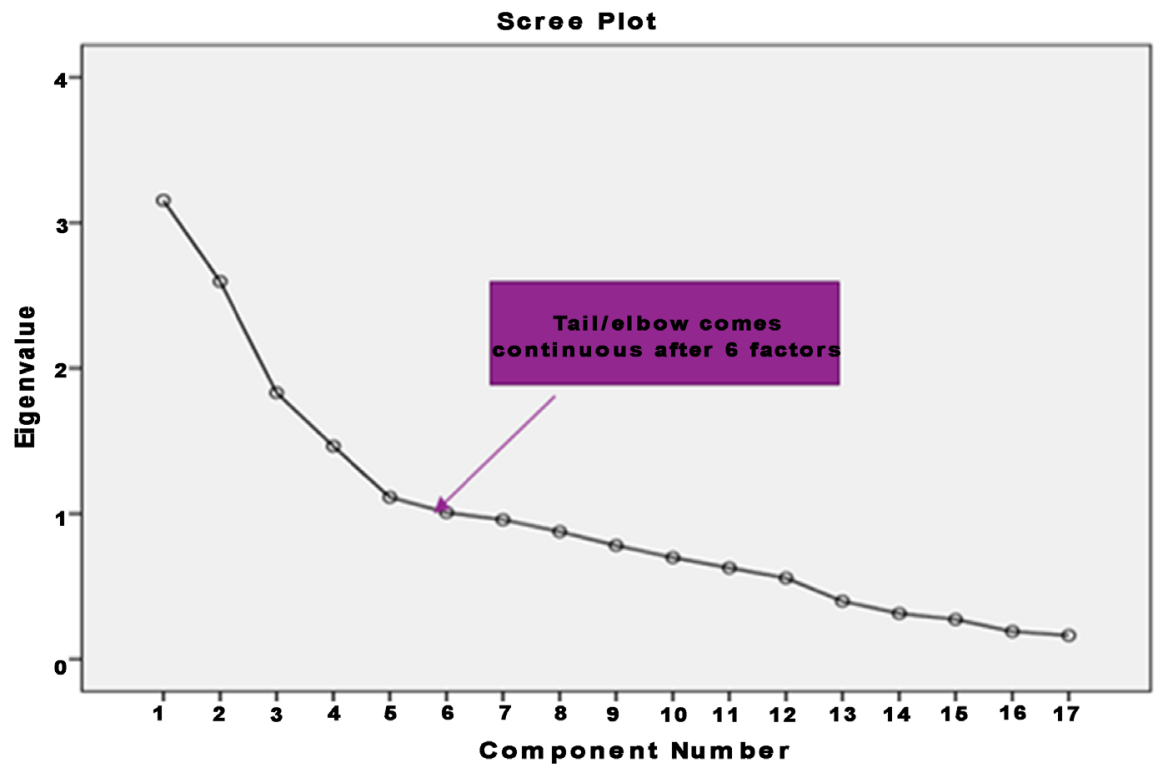

Figure 2. Scree Plot for factors extracted after rotation of variables for consumer's attitude towards gluten-free foods in USA. Source: Researcher's own compiled primary data.

Taste, smell, product appearance and quality loaded on factor 2. Thus factor 2 could be named as Product features. Factor 2 had variance of 14.85 percent. All the consumers of gluten-free foods crave for tasty and healthy foods. Many times healthy foods did not taste good e.g. according to few consumers multigrain breads tasted like dry paper. Foods which were tasty e.g. chocolate muffins, pastries, cookies, cake, pizza etc. were very high in sugar and fats, thus making the consumers unhealthy and fat. So there was very high demand of gluten-free foods which were good in taste and texture but at the same time ensured high quality in terms of ingredients and nutrients.

Availability and promotion loaded on factor 3 . Thus factor 3 could be named as Place \& promotion. Factor 3 had variance of 11.58 percent. The factor tells about which segment of consumers to target and which products should be made available at a particular location. Many companies of gluten-free foods did not focus on place \& promotion, thus they were unable to capture the market in spite of having high demand of gluten-free foods. E.g., food stores near university campus shall focus more on salty snacks, chips and cookies because they were being preferred by students. However few stores just kept gluten-free bakery products and no or very less snacks which reduced their sales.

Social status and awareness loaded on factor 4 . Thus factor 4 could be named as Social awareness. Factor 4 had variance of 8.94 percent. Awareness was pre-cursor for sales and increased demand. Very few consumers preferred buying any new product which was expensive than normal products and was not popular. Social awareness about gluten-free foods could be created through celiac meet ups and visits to different gluten-free stores and bakeries, events highlighting the benefits of gluten-free products, web portals and blogs etc. Com- 
panies who want to succeed should also focus on non-allergy consumers apart from allergy patients by highlighting the health benefits of gluten-free foods.

Price and doctor recommendation loaded on factor 5. Thus factor 5 could be named as Product Sale. Factor 5 had variance of 7.05 percent. Product sales was mainly dependent on price of the product and effective recommendation or reference preferably someone from medicine background e.g., doctor, dietician, nutritionist etc. Consumer preferred to buy most affordable products out of the given recommendations which were good in taste and quality.

Knowledge and brand image loaded on factor 6 . Thus factor 6 could be named as Product visibility. Factor 6 had variance of 6.36 percent. Product visibility enhanced the sales by creating impulse in consumers to buy or try products which were healthy like Dr. Schar, Udi's, Glutino etc. Thus stores should try to increase product visibility by keeping the branded products in front shelves to attract more consumers.

The results of the study were found different with Mintel Data (2014). According to Mintel Data (2014) product taste and smell were most important factors from consumer's point of view. However in our study it was found that in India packaging was most important factor and in USA safe food attribute was most important factor.

\section{Conclusion}

India and USA, both the countries depicted huge difference in consumer preferences related to gluten-free foods. In factor analysis of India, four factors were identified based on variables loading. The awareness, brand image, food safety certification, packaging options and other users in vicinity load on factor 1 (named as brand packaging). The taste, smell, product appearance and quality load on factor 2 (named as Product Features). The availability, promotion, social status and doctor recommendation load on factor 3 (named as Place \& Promotion). The price, knowledge, claims and labelling information recommendation load on factor 4 (named as pricing and labelling). In factor analysis of USA, 6 factors are identified based on variables loadings. The food safety certification, claims, packaging options, labelling information and other users in vicinity load on factor 1 (named as Safe food attributes). The taste, smell, product appearance and quality load on factor 2 (named as Product features). The availability and promotion load on factor 3 (named as Place $\&$ promotion). The social status and awareness load on factor 4 (named as Social awareness). The price and doctor recommendation load on factor 5 (named as Product Sale). The knowledge and brand image load on factor 6 (named as Product visibility). Thus study would help manufacturers of alternative wheat product to form a concrete marketing and product development strategy based on recent consumer behavior trends.

\section{References}

[1] Sheluga, D. (2014) The Truth about Gluten Free: Market Size and Consumer Beha- 
vior for Successful Business Decisions. Ardent Mills, 6, 14

[2] Poltechnic, M. (2016) A Global Map of Celiac Disease. Dr Schar Institute. http://www.drschaer-institute.com/us/professional-articles/a-global-map-of-celiacdisease-1229.html

[3] House, L. (2016) Is Gluten-Free the Most Expensive Fad Yet? Average Family Can't Afford to Follow the Diet with Everyday Staples like Bread and Flour Costing up to 500 PERCENT More. Daily Mail, London, 1, 11.

[4] Anonymous (2014) Food Choice. Canadian Celiac Association. http://www.celiac.ca/?page_id=299

[5] Makharia, G.K. (2014) Current and Emerging Therapy for Celiac Disease. Frontiers of Medicine, 1, 6. https://doi.org/10.3389/fmed.2014.00006

[6] Anonymous (2016) Free-From Gains Momentum: Sales of Free-From Food Products Forecast to Surpass Half a Billion in the UK in 2016. Mintel.

http://www.mintel.com/press-centre/food-and-drink/free-from-gains-momentum-s ales-of-free-from-food-products-forecast-to-surpass-half-a-billion-in-the-uk-in-201 $\underline{6}$ 